\title{
Changes in sperm quality and lipid composition during cryopreservation of boar semen
}

\author{
S. Cerolini ${ }^{1}$, A. Maldjian², F. Pizzi ${ }^{3}$ and T. M. Gliozzi ${ }^{3}$ \\ ${ }^{1}$ Istituto di Zootecnica, Facoltà di Medicina Veterinaria, Università di Milano, via Celoria 10, \\ 20133 Milano, Italy; ${ }^{2}$ Biochemistry and Nutrition Department, Scottish Agricultural College, \\ Auchincruive KA6 5HW, UK; and I'Istituto per la Difesa e Valorizzazione del Germoplasma \\ Animale, Consiglio Nazionale delle Ricerche, via Celoria 10, 20133 Milano, Italy
}

The effect of cryopreservation on boar sperm viability, motility, lipid content and antioxidant enzymatic activities was studied. Three classes of semen were determined according to a cluster analysis on the basis of the proportion of live and dead cells after freezing and thawing. The classes identified were: high $(H, n=4)$, average $(A, n=12)$ and low ( $L, n=3)$ viability. The concentration of sperm cells decreased from class $\mathbf{H}$ to $A$ to $L$. Fresh semen samples with higher viability and a higher proportion of motile cells also maintained better quality after the freezing and thawing procedure. Sperm viability and motility in both fresh and thawed samples were similar in classes $\mathrm{H}$ and $\mathrm{A}$, while significantly lower values were measured in class $L$. The relative decrease in sperm viability and motility after cryopreservation increased from class $\mathrm{H}$ to $\mathrm{A}$ to $\mathrm{L}$. The lipid content of spermatozoa ( $\mu$ g per $10^{9}$ cells) increased significantly after freezing and thawing in classes $\mathrm{H}$ and $\mathrm{A}$ but not in class $\mathrm{L}$. This result indicated that active sperm lipid metabolism might be responsible for the increase in lipid content. Phospholipid and triacylglycerol contents increased whereas free cholesterol content decreased after thawing. The fatty acid composition of fresh spermatozoa was similar in all three classes. The proportion of polyunsaturated fatty acids decreased significantly after freezing and thawing, indicating contamination from the diluent or peroxidation. After freezing and thawing, superoxide dismutase activity in spermatozoa was significantly higher in class $L$ than in classes $H$ and $A$, which did not differ from each other.

\section{Introduction}

Cryopreservation of boar semen is rarely performed in commercial practice. The main reasons for this are the poor survival rate of spermatozoa and, as a consequence, the high concentration required in the insemination dose. Refrigeration at $16-18^{\circ} \mathrm{C}$ is the usual method of storing boar semen for a few days and good or acceptable fertility rates are obtained compared with fresh samples. Nevertheless, cryopreservation is a valuable technique, especially for the conservation of genetic resources (that is, through sperm banks), or to ensure a constant commercial supply of semen doses in the case of a temporary epidemiological problem or of impaired semen production as a result of adverse climatic conditions (that is, in hot countries). Cryopreservation affects sperm membrane integrity (for reviews, see Bwanga, 1991; Watson, 1995). Differences in fatty acid composition and lipid class ratios in spermatozoa among species are important factors in the freezability of the male gametes (Parks and Lynch, 1992). Pettitt and Buhr (1998) reported lipid modifications due to freezing and thawing and also indicated that domains of sperm head plasma

Email: silvia.cerolini@unimi.it membrane react differently to cryopreservation. Furthermore, some studies (Neill and Masters, 1972, 1973; Vasquez and Roldan, 1997) investigated the ability of sperm cells to take up lipid components or fatty acids from the surrounding environment during incubation in vitro.

The present study focused on the effect of cryopreservation on traditional quality parameters, lipid composition and antioxidant enzymatic changes in boar semen samples classified according to the ability of spermatozoa to survive the freezing and thawing procedure. The aim was to study the effect of the initial sperm quality (that is, before freezing) on freezability, and also on the lipid exchanges between sperm cells and diluent occurring during freezing. Furthermore, the feasibility of using lipid components as markers to predict the ability of a sample to survive the freezing and thawing procedure was investigated.

\section{Materials and Methods}

\section{Sperm collection and freezing and thawing procedure}

Semen samples were collected by the gloved-hand technique from 19 boars, $1-5$ years old, of different genetic lines (Landrace, Large White and commercial hybrids). Animals were housed and bred in an Artificial Insemination 
Centre (ELPZOO Spa, Lodi) in accordance with the Italian and European Union legislation. An aliquot of the spermrich fraction was diluted $1: 2(\mathrm{v}: \mathrm{v})$ in Beltsville thawing solution (BTS, $41 \mathrm{~g}$ D+ glucose, $1.25 \mathrm{~g}$ sodium hydrogen carbonate, $1.25 \mathrm{~g}$ EDTA, $6 \mathrm{~g}$ trisodium citrate, $0.75 \mathrm{~g}$

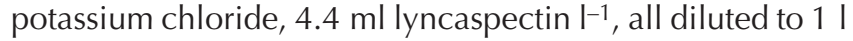
in distilled water) and used for assessment of fresh semen quality and sperm lipid analysis. The remainder of the ejaculate was frozen according to the procedure of Westendorf et al. (1975) modified by Almlid et al. (1987), in $4 \mathrm{ml}$ multi-mini straws (ZM-SYS- $411^{\circledR}$, ELPZOO Spa, Lodi) at a concentration of $500 \times 10^{6}$ cells $\mathrm{ml}^{-1}$ and stored in liquid nitrogen. The straws were thawed in a water bath at $37^{\circ} \mathrm{C}$ for $2 \mathrm{~min}$; semen was transferred into a glass tube and diluted $1: 4(\mathrm{v}: \mathrm{v})$ in the thawing extender at $20^{\circ} \mathrm{C}$.

\section{Sperm quality parameters}

Sperm concentration, motility, viability and lipid composition were assessed in fresh and frozen-thawed samples. Sperm concentration was measured by Coulter counter (Coulter ${ }^{\circledR}$ Z1). Sperm motility was assessed subjectively under a microscope (Nikon Diaphot, contrast phase 2, ELWD $0.3, \times 10)$ after $10 \mathrm{~min}$ incubation in a water bath at $37^{\circ} \mathrm{C}$ for fresh samples, and after 1,4 and $6 \mathrm{~h}$ incubation at $37^{\circ} \mathrm{C}$ for thawed samples. Sperm viability was assessed according to the SYBR 14/propidium iodide (Molecular Probes Inc., Eugene, OR) fluorescent procedure (Garner and Johnson, 1995): live, dead and moribund (dual staining) cells were counted under a fluorescence microscope (Leitz Aristoplan) and the proportion of each category was calculated.

\section{Sperm lipid composition}

Washed spermatozoa from fresh and thawed samples were obtained after two centrifugations: the first at $850 \mathrm{~g}$ at $18^{\circ} \mathrm{C}$ for $20 \mathrm{~min}$ and the second at $1900 \mathrm{~g}$ at $5^{\circ} \mathrm{C}$ for $20 \mathrm{~min}$. Cell pellets were washed with BTS after the first centrifugation. Total lipids were extracted in excess chloroform: methanol $(2: 1)(\mathrm{v}: \mathrm{v})$ from the washed spermatozoa. A minimum of $1 \times 10^{9}$ cells was used for lipid analysis. Phospholipids, triacylglycerols and free cholesterol were the major lipid classes separated by thin layer chromatography (TLC) on silica gel G60 (Merck, Darmstadt, D) using a solvent system of hexane:diethyl ether:formic acid (80:20:1)(v:v:v) (Sigma Chemical Co., St Louis, MO). After spraying the TLC plate with $0.1 \%(\mathrm{w} / \mathrm{v})$ 2,7-dichlorofluorescein (Sigma) in methanol, the phospholipid, triacylglycerol and free cholesterol bands, visualized under UV light, were scraped from the plate. Phospholipids were eluted from the silica by washing twice with methanol, and triacylglycerols and free cholesterol were washed with diethyl ether. The fatty acids were trans-methylated by refluxing with a mixture of methanol:toluene:sulphuric acid (20:10:1) (v:v:v) in the presence of a pentadecanoic acid standard (Sigma) (Hamilton et al., 1992). The resultant fatty acid methyl esters were analysed by injection via a CP9010 autosampler (Chrompack,
Speck Analytical, London) onto a $30 \mathrm{~mm} \times 0.25 \mathrm{~mm}$ in diameter, $0.25 \mu \mathrm{m}$ film thickness Carbowax capillary column (Alltech Ltd, Carnforth) fitted to a Chrompack CP9001 gas chromatograph. The data processing system (EZ-Chrom Data Handling System, Speck Analytical, UK) enabled the expression of the fatty acid composition in terms of proportion by weight. The identification of the peak values was confirmed by comparison with the retention times of standard fatty acid methyl ester mixtures (Sigma). The amount of each lipid class was calculated by comparison of the total fatty acid peak value areas to that of the pentadecanoic fatty acid standard (Christie et al., 1970). Free cholesterol was determined by standard colorimetric assay (Boehringer Mannheim Spa, Monza). The absolute, $\mu \mathrm{g}$ per $10^{9}$ cells and relative percentage contents of the lipid classes were calculated. The ratio of free cholesterol: phospholipids was calculated on the absolute content in $\mu g$ per $10^{9}$ cells. The lipid composition of the egg yolk-based freezing extender was carried out following the same procedure.

\section{Superoxide dismutase and glutathione peroxidase assays}

Superoxide dismutase (SOD), total glutathione peroxidase (GSH-Px) and selenium-dependent glutathione peroxidase (GSH-Px-Se) activities were measured in both seminal plasma and spermatozoa of fresh samples and in only the spermatozoa of cryopreserved samples owing to the egg yolk contamination from the diluent. Spermatozoa were separated and washed by centrifugation as described above and seminal plasma obtained from the first centrifugation was transferred into a clean tube, centrifuged again at $1900 \mathrm{~g}$ at $5^{\circ} \mathrm{C}$ for $20 \mathrm{~min}$ and the supernatant stored frozen until assayed for enzymatic activity. Washed spermatozoa were suspended in $1 \mathrm{ml}$ BTS, sonicated for $2 \mathrm{~min}$ in ice (power 5, duty cycle 10, Branson Sonifier 250), centrifuged at $1900 \mathrm{~g}$ at $5^{\circ} \mathrm{C}$ for $30 \mathrm{~min}$ and the supernatant stored frozen at $-20^{\circ} \mathrm{C}$ for enzymatic assays. Total SOD activity was measured by the colorimetric xanthine-xanthine oxidase method using the Ransod kit (Randox Laboratories Ltd, Crumlin) (Woolliams et al., 1983). The GSH-Px activity was measured by colorimetric method, with the total enzyme activity measured using cumene hydroperoxide as a substrate (Ransel kit, Randox Laboratories Ltd) (Ammerman et al., 1980) and the selenium-dependent activity using 3\% hydrogen peroxide solution as a substrate.

\section{Statistical analysis}

Hierarchical cluster analysis (SCAN, 1995) was carried out to classify the boars according to the proportion of live and dead cells measured after freezing and thawing. The proportion of moribund spermatozoa was not included in the analysis to avoid redundant information. General linear model (GLM) procedure (SAS, 1998) was undertaken to assess the difference between the different classes. The following sources of variation were considered in the model: the genetic line of the boar (Landrace, Large White 


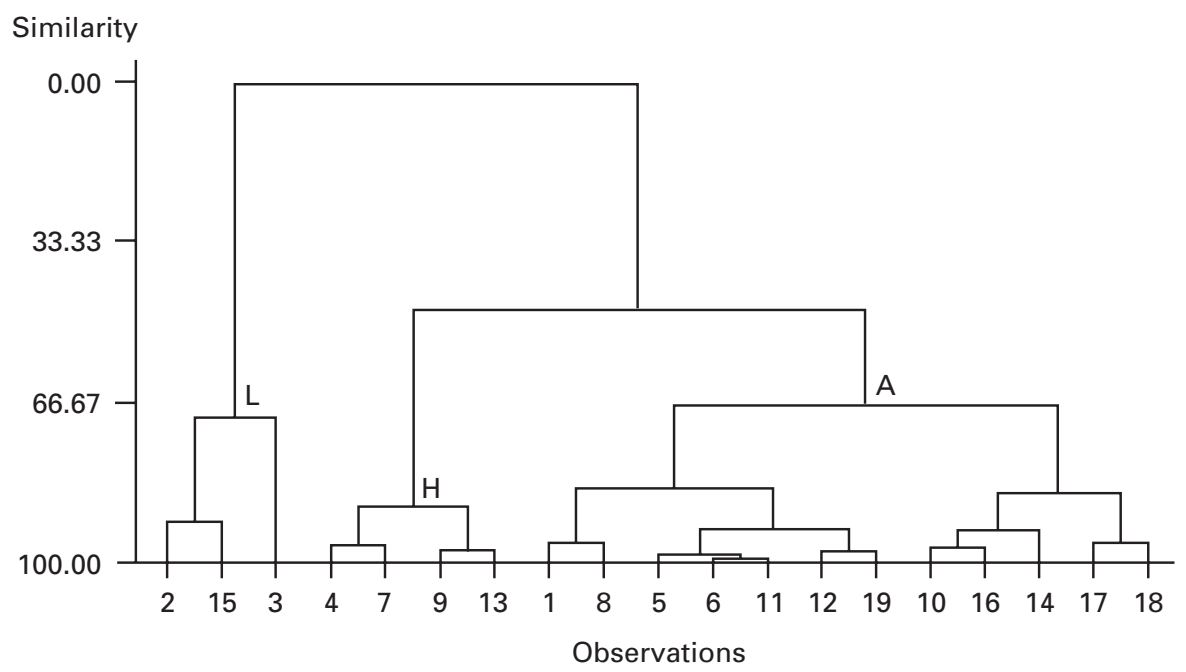

Fig. 1. Dendrogram showing the similarity of boars according to the proportion of live and dead spermatozoa measured after freezing and thawing. The numbers on the horizontal axis represent the 19 boars of the study, the vertical axis shows the proportion of similarity. The low $(\mathrm{L})$, high $(\mathrm{H})$ and average $(\mathrm{A})$ viability classes were determined by cutting the dendrogram at the similarity level of $67.4 \%$.

and commercial hybrids), the freezability classes $(\mathrm{H}, \mathrm{A}$ and $\mathrm{L}$ ) and the storage (fresh and frozen-thawed). The age of the boar was also included in the statistical model as covariate. Student's $t$ test was used for comparison between least square means.

\section{Results}

\section{Semen quality}

The dendrogram obtained by hierarchical analysis of semen according to the proportion of live and dead cells after freezing and thawing is represented (Fig. 1). Three classes were obtained by cutting the dendrogram at the similarity level of $67.4 \%$, namely: highest $(H)$, average $(A)$ and lowest (L) proportion of live cells (Table 1). Most boars $(n=12)$ were included in class A, but $n$ was 4 and 3 for classes $\mathrm{H}$ and $\mathrm{L}$, respectively. Such a distribution is comparable to a normal distribution.

Sperm concentration decreased progressively from classes $\mathrm{H}$ through $\mathrm{A}$ to $\mathrm{L}$, with $425.0 \pm 98.4,340.0 \pm 40.9$ and $303.0 \pm 73.1 \times 10^{6}$ cells $\mathrm{ml}^{-1}$, respectively.

The freezing and thawing procedure led to a decrease in sperm viability and motility in all classes. Semen samples with the higher proportion of live cells after freezing and thawing also had a higher proportion of live cells before freezing. Sperm viability in fresh samples was significantly higher in classes $\mathrm{H}$ and $\mathrm{A}$ compared with class $\mathrm{L}$, and the same trend was observed after freezing and thawing (Table 1). As expected, the proportion of dead cells showed a complementary pattern to the proportion of viable cells. The proportion of moribund cells did not differ among the classes either in fresh or frozen semen samples, but it was significantly reduced in stored compared with fresh samples within each class. The relative decreases in the number of live cells owing to the freezing procedure, calculated as the proportions of the difference on the initial value were 45.5, 52.5 and $66.1 \%$ in classes $\mathrm{H}, \mathrm{A}$ and L, respectively.

The proportion of motile cells did not differ among the classes in fresh semen and was significantly decreased, as was viability, in all three classes after freezing and thawing. The loss of motility (fresh versus $1 \mathrm{~h}$ after thawing) increased progressively from classes $\mathrm{H}$ to $\mathrm{L}(29.4,32.2$ and $50.9 \%$ for classes $\mathrm{H}, \mathrm{A}$ and $\mathrm{L}$, respectively). However, only the motility of class $L$ differed significantly from classes $\mathrm{H}$ and $\mathrm{A}$, which had similar values (Table 1 ). The relative losses of motility in spermatozoa stored from 1 to $6 \mathrm{~h}$ at $37^{\circ} \mathrm{C}$ after freezing and thawing were $25,26.6$ and $33.2 \%$ in classes $\mathrm{H}, \mathrm{A}$ and $\mathrm{L}$, respectively (Table 1 ).

\section{Sperm lipid composition}

A large variability was found in the total lipid (TL) content of fresh spermatozoa of different boars and the individual values ranged from 236 to $1400 \mu \mathrm{g}$ per $10^{9}$ cells. The average TL content in class $\mathrm{H}$ was lower than it was in classes $A$ and $L$, but the difference was not significant (Table 2).

All fresh spermatozoa showed a similar lipid class composition, with phospholipids accounting for $75-78 \%$ of total lipids (Table 2). Free cholesterol was the second major lipid class, accounting for $24 \%$ of total lipid. Triacylglycerols were not detected in fresh cells.

After thawing, the absolute amount of TL increased significantly in classes $\mathrm{H}$, in which the amount almost doubled, and A; TL also increased in class $L$ but the difference was not significant (Table 2), indicating that the viability of spermatozoa before freezing is a determinant 
Table 1. Sperm viability (percentage of live, dead and moribund cells) and motility (percentage of motile cells soon after ejaculation or after 1, 4 and $6 \mathrm{~h}$ of incubation at $37^{\circ} \mathrm{C}$ ) in boar semen samples classified by high, average and low viability after freezing and thawing

\begin{tabular}{|c|c|c|c|c|c|c|}
\hline & \multicolumn{3}{|c|}{ Fresh semen } & \multicolumn{3}{|c|}{ Frozen-thawed semen } \\
\hline & $\mathrm{H}$ & A & $\mathrm{L}$ & $\mathrm{H}$ & A & $\mathrm{L}$ \\
\hline Live & $77.5 \pm 3.7^{\mathrm{aA}}$ & $73.0 \pm 1.7^{\mathrm{aA}}$ & $58.4 \pm 3.7^{\mathrm{aB}}$ & $42.2 \pm 3.7^{\mathrm{bA}}$ & $34.7 \pm 1.7^{\mathrm{bA}}$ & $19.9 \pm 3.7^{\mathrm{bB}}$ \\
\hline Dead & $17.6 \pm 3.3^{\mathrm{aA}}$ & $23.5 \pm 1.6^{\mathrm{aA}}$ & $38.3 \pm 3.3^{\mathrm{aB}}$ & $56.6 \pm 3.3^{\mathrm{bA}}$ & $64.8 \pm 1.6^{\mathrm{bB}}$ & $79.3 \pm 3.3^{\mathrm{bc}}$ \\
\hline Moribund & $5.0 \pm 1.2^{\mathrm{a}}$ & $3.9 \pm 0.6^{\mathrm{a}}$ & $3.2 \pm 1.2$ & $1.2 \pm 1.2^{b}$ & $0.5 \pm 0.6^{b}$ & $0.9 \pm 1.2$ \\
\hline Motility & $63.2 \pm 2.2$ & $62.1 \pm 1.2$ & $56.4 \pm 2.5$ & - & - & - \\
\hline Motility $1 \mathrm{~h}$ & - & - & - & $44.6 \pm 4.4^{\mathrm{A}}$ & $42.1 \pm 2.4^{\mathrm{A}}$ & $27.7 \pm 5.0^{\mathrm{B}}$ \\
\hline Motility $4 \mathrm{~h}$ & - & - & - & $37.1 \pm 5.0^{\mathrm{AB}}$ & $37.6 \pm 2.8^{\mathrm{B}}$ & $22.5 \pm 5.8^{\mathrm{A}}$ \\
\hline Motility $6 \mathrm{~h}$ & - & - & - & $33.5 \pm 5.6$ & $30.9 \pm 3.1$ & $19.0 \pm 6.4$ \\
\hline
\end{tabular}

The low $(\mathrm{L})$, high $(\mathrm{H})$ and average $(\mathrm{A})$ viability classes were determined by cutting the dendrogram at the similarity level of $67.4 \%$.

Values are means \pm SEM.

${ }^{a b}$ Within class, values with different superscripts are significantly different $(P<0.05)$; ${ }^{A B C}$ within type of storage, values with different superscripts are significantly different $(P<0.05)$.

Table 2. Total lipid and lipid classes of washed sperm cells in boar semen samples classified by high, average and low viability after freezing and thawing

\begin{tabular}{|c|c|c|c|c|c|c|}
\hline & \multicolumn{3}{|c|}{ Fresh semen } & \multicolumn{3}{|c|}{ Frozen-thawed semen } \\
\hline & $\mathrm{H}$ & A & L & $\mathrm{H}$ & A & L \\
\hline \multicolumn{7}{|c|}{$\mu g$ per $10^{9}$ spermatozoa } \\
\hline $\mathrm{TL}$ & $595.7 \pm 181.0^{\mathrm{a}}$ & $728.5 \pm 84.8^{a}$ & $729.8 \pm 179.9$ & $1243.9 \pm 181.0^{\mathrm{b}}$ & $1193.1 \pm 84.8^{b}$ & $1084.9 \pm 179.9$ \\
\hline$P L$ & $459.9 \pm 106.0$ & $558.9 \pm 49.6^{a}$ & $552.3 \pm 105.3$ & $690.9 \pm 106.0$ & $724.4 \pm 49.7^{b}$ & $616.9 \pm 105.3$ \\
\hline FC & $143.3 \pm 29.9$ & $168.0 \pm 14.0^{\mathrm{a}}$ & $172.8 \pm 29.7$ & $104.6 \pm 29.9$ & $121.1 \pm 14.0^{\mathrm{b}}$ & $105.8 \pm 29.7$ \\
\hline TG & nd & nd & nd & $440.7 \pm 158.2$ & $349.0 \pm 72.4$ & $367.9 \pm 156.6$ \\
\hline $\mathrm{FC}: \mathrm{PL}$ & $0.31 \pm 0.07$ & $0.34 \pm 0.03^{\mathrm{a}}$ & $0.32 \pm 0.06$ & $0.15 \pm 0.07$ & $0.16 \pm 0.03^{b}$ & $0.17 \pm 0.06$ \\
\hline \multicolumn{7}{|c|}{ Percentage of total lipid } \\
\hline$P L$ & $77.7 \pm 6.9$ & $75.5 \pm 3.2$ & $74.9 \pm 6.8$ & $63.9 \pm 6.9$ & $63.5 \pm 3.2$ & $55.8 \pm 6.8$ \\
\hline FC & $23.6 \pm 3.4$ & $24.5 \pm 1.6$ & $24.1 \pm 3.4$ & $7.4 \pm 3.4$ & $10.1 \pm 1.6$ & $9.7 \pm 3.4$ \\
\hline TG & - & - & - & $31.0 \pm 8.3$ & $23.5 \pm 3.8$ & $28.7 \pm 8.2$ \\
\hline
\end{tabular}

The low $(\mathrm{L})$, high $(\mathrm{H})$ and average $(\mathrm{A})$ viability classes were determined by cutting the dendrogram at the similarity level of $67.4 \%$.

FC: free cholesterol; FC:PL: free cholesterol:phospholipid ratio; PL: phospholipids; TG: triacylglycerols; TL: total lipid.

Values are means \pm SEM.

abWithin class, values with different superscripts are significantly different $(P<0.05)$; nd: not detected.

factor for cellular lipid enrichment from the surrounding medium. The increase in the amount of TL was due to a major increase in triacylglycerol content and, to a lesser extent, to an increase in phospholipid content. In contrast, a loss of free cholesterol was measured in all three classes and the decrease was significant in class A when compared with fresh spermatozoa. The proportions of phospholipid and free cholesterol decreased after thawing as a consequence of the increase in triacylglycerol. Triacylglycerols were not detected in fresh samples but accounted for up to $762 \mu \mathrm{g}$ per $10^{9}$ spermatozoa after freezing. Triacylglycerols are well represented in egg yolk and an interaction between gametes and the egg yolk-based diluent is suggested as the major cause of the described changes in lipid composition. The free cholesterol:phospholipid ratio was similar among classes within fresh and stored samples and was halved after freezing and thawing because of the decrease in the free cholesterol content (Table 2).

The fatty acid composition of the sperm phospholipids did not differ greatly among the three classes, either for fresh or stored semen (Table 3). As expected, palmitic acid (16:0) was the major saturate, and docosapentaenoic (22:5n-6) and docosahexaenoic (22:6n-3) acids were the major polyunsaturates in fresh spermatozoa. The fatty acid compositions of phospholipid and triacylglycerol in the diluent were mainly represented by saturated (16:0) and monounsaturated (18:1n-9) fatty acids (Table 3 ). The effects of both the freezing procedure and the diluent on sperm phospholipid were to increase significantly the proportion of the most important saturates (16:0 and 18:0), mono-unsaturate (18:1n-9) and linoleic acid (18:2n-6) (Table 3). The relative content of total polyunsaturated fatty acids (PUFA) in frozen-thawed spermatozoa decreased significantly in all classes compared with fresh cells, either as a consequence of the relative increase in the proportions of saturated or of actual loss of PUFA owing to the stress of cryopreservation (resulting in, for example, membrane damage and peroxidation). 
Table 3. Relative fatty acid composition of phospholipid in boar spermatozoa and of phospholipid and triacylglycerols in freezing diluent (semen samples are classified by high, average and low viability after freezing and thawing)

\begin{tabular}{|c|c|c|c|c|c|c|c|c|}
\hline \multirow[b]{2}{*}{ Fatty acid } & \multicolumn{3}{|c|}{ Fresh semen } & \multicolumn{3}{|c|}{ Frozen-thawed semen } & \multicolumn{2}{|c|}{ Diluent } \\
\hline & $\mathrm{H}$ & A & $\mathrm{L}$ & $\mathrm{H}$ & A & $\mathrm{L}$ & $\mathrm{PL}$ & TG \\
\hline $14: 0$ & $4.0 \pm 0.5^{a}$ & $3.5 \pm 0.3^{\mathrm{a}}$ & $4.3 \pm 0.6^{a}$ & $1.9 \pm 0.5^{b}$ & $2.0 \pm 0.3^{b}$ & $2.5 \pm 0.6^{b}$ & $<0.5$ & $<0.5$ \\
\hline $16: 0$ & $15.2 \pm 0.6^{\mathrm{a}}$ & $15.1 \pm 0.3^{\mathrm{a}}$ & $15.1 \pm 0.7^{a}$ & $19.1 \pm 0.6^{b}$ & $19.4 \pm 0.3^{b}$ & $19.4 \pm 0.7^{b}$ & 26.9 & 23.9 \\
\hline 18:0 & $6.7 \pm 0.4^{\mathrm{a}}$ & $6.4 \pm 0.2^{\mathrm{a}}$ & $5.9 \pm 0.5^{a}$ & $10.3 \pm 0.4^{b}$ & $10.2 \pm 0.2^{b}$ & $9.9 \pm 0.5^{b}$ & 15.1 & 6.0 \\
\hline $18: 1 n-9$ & $1.5 \pm 0.8^{\mathrm{a}}$ & $1.9 \pm 0.5^{a}$ & $2.1 \pm 1.0^{\mathrm{a}}$ & $9.5 \pm 0.8^{b}$ & $10.1 \pm 0.5^{b}$ & $11.0 \pm 1.0^{b}$ & 24.0 & 48.0 \\
\hline $18: 2 n-6$ & $2.5 \pm 0.8^{\mathrm{a}}$ & $2.4 \pm 0.4^{\mathrm{a}}$ & $2.7 \pm 0.9^{a}$ & $5.0 \pm 0.8^{\mathrm{bA}}$ & $7.0 \pm 0.4^{\mathrm{bB}}$ & $7.8 \pm 0.9^{\mathrm{bB}}$ & 15.1 & 15.8 \\
\hline $20: 3 n-6$ & $1.5 \pm 0.1^{\mathrm{a}}$ & $1.5 \pm 0.1^{\mathrm{a}}$ & $1.2 \pm 0.2$ & $0.8 \pm 0.1^{\mathrm{b}}$ & $1.1 \pm 0.1^{b}$ & $0.8 \pm 0.2$ & $<0.5$ & $<0.5$ \\
\hline $20: 4 n-6$ & $3.2 \pm 0.2^{\mathrm{a}}$ & $3.3 \pm 0.1^{\mathrm{a}}$ & $3.3 \pm 0.2^{\mathrm{a}}$ & $4.4 \pm 0.2^{b}$ & $4.4 \pm 0.1^{b}$ & $4.3 \pm 0.2^{b}$ & 6.5 & $<0.5$ \\
\hline $22: 4 n-6$ & $2.5 \pm 0.2^{\mathrm{aAB}}$ & $2.4 \pm 0.1^{\mathrm{aB}}$ & $2.9 \pm 0.2^{\mathrm{aA}}$ & $1.9 \pm 0.2^{b}$ & $1.7 \pm 0.1^{b}$ & $1.9 \pm 0.2^{b}$ & nd & $<0.5$ \\
\hline $22: 5 n-6$ & $29.1 \pm 2.4^{a}$ & $31.0 \pm 1.4^{\mathrm{a}}$ & $32.3 \pm 2.8^{a}$ & $21.1 \pm 2.4^{b}$ & $20.8 \pm 1.4^{b}$ & $21.5 \pm 2.8^{b}$ & 2.5 & $<0.5$ \\
\hline $22: 6 n-3$ & $29.6 \pm 3.1$ & $28.1 \pm 1.8^{a}$ & $29.3 \pm 3.6$ & $22.0 \pm 3.1$ & $19.3 \pm 1.8^{b}$ & $17.1 \pm 3.6$ & 2.7 & $<0.5$ \\
\hline SFA & $26.5 \pm 1.2^{\mathrm{a}}$ & $25.7 \pm 0.7^{a}$ & $26.0 \pm 1.4^{\mathrm{a}}$ & $31.9 \pm 1.2^{b}$ & $32.2 \pm 0.7^{b}$ & $32.4 \pm 1.4^{b}$ & - & - \\
\hline PUFA & $69.3 \pm 2.0^{\mathrm{a}}$ & $69.7 \pm 1.1^{\mathrm{a}}$ & $69.7 \pm 2.3^{a}$ & $55.9 \pm 2.0^{b}$ & $55.1 \pm 1.1^{b}$ & $54.2 \pm 2.3^{b}$ & - & - \\
\hline$P: S$ & $2.6 \pm 0.2^{\mathrm{a}}$ & $2.7 \pm 0.1^{a}$ & $2.8 \pm 0.2^{\mathrm{a}}$ & $1.8 \pm 0.2^{b}$ & $1.7 \pm 0.1^{b}$ & $1.7 \pm 0.2^{b}$ & - & - \\
\hline
\end{tabular}

The low $(\mathrm{L})$, high $(\mathrm{H})$ and average $(\mathrm{A})$ viability classes were determined by cutting the dendrogram at the similarity level of $67.4 \%$.

Values are means \pm SEM.

abWithin class, values with different superscripts are significantly different $(P<0.05)$; ${ }^{A B}$ within type of storage, values with different superscripts are significantly different $(P<0.05)$; nd: not detected; SFA: total saturates; PUFA: total polyunsaturates; P:S: polyunsaturates:saturates ratio.

Table 4. Superoxide dismutase (SOD), total glutathione peroxidase (GSH-Px) and proportion of the selenium-dependent glutathione peroxidase (GSH-Px-Se) activities in spermatozoa (spz) and seminal plasma (pl) of boar semen samples classified by high, average and low viability after freezing and thawing

\begin{tabular}{|c|c|c|c|}
\hline & $\mathrm{H}$ & A & L \\
\hline \multicolumn{4}{|l|}{ Fresh semen } \\
\hline SOD spz (iu mg ${ }^{-1}$ protein) & $333.2 \pm 135.8$ & $374.4 \pm 72.0$ & $283.2 \pm 165.6$ \\
\hline SOD pl (iu mg ${ }^{-1}$ protein) & $5.7 \pm 1.3$ & $7.4 \pm 0.7$ & $5.8 \pm 1.6$ \\
\hline GSH-Px pl (iu g ${ }^{-1}$ protein) & $6.68 \pm 2.8$ & $8.8 \pm 1.6$ & $8.2 \pm 3.5$ \\
\hline GSH-Px-Se pl (\%) & $90.8 \pm 10.0$ & $85.8 \pm 4.7$ & $80.7 \pm 10.7$ \\
\hline \multicolumn{4}{|l|}{ Frozen-thawed semen } \\
\hline SOD spz (iu mg m $^{-1}$ protein) & $502.2 \pm 56.8^{\mathrm{a}}$ & $456.7 \pm 21.5^{a}$ & $847.6 \pm 99.5^{b}$ \\
\hline
\end{tabular}

The low $(\mathrm{L})$, high $(\mathrm{H})$ and average $(\mathrm{A})$ viability classes were determined by cutting the dendrogram at the similarity level of $67.4 \%$.

Values are means \pm SEM.

abWithin type of storage, values with different superscripts are significantly different $(P<0.05)$.

\section{Antioxidant enzyme activities}

SOD activity was measured in boar spermatozoa but GSH-Px activity was not detected. In contrast, both enzymatic activities were measured in seminal plasma (Table 4). A large variability in SOD activity was found among the spermatozoa of different boars, with concentrations ranging from 167.7 to 926.6 and from 3.32 to $13.8 \mathrm{iu} \mathrm{mg}^{-1}$ protein in spermatozoa and seminal plasma, respectively. Concentrations of GSH-Px ranged from 2.67 to $16.3 \mathrm{iu} \mathrm{g}^{-1}$ protein in seminal plasma and the proportion of GSH-Px-Se ranged from 67 to $100 \%$ of the total activity. In fresh semen, no significant differences were found among the classes of spermatozoa in terms of antioxidant activities. After freezing and thawing, sperm SOD activity increased in all classes, with a particularly marked difference in class L, which showed a significantly higher activity than those of classes $\mathrm{H}$ and $\mathrm{A}$ (Table 4).

\section{Discussion}

Semen quality in boars is affected markedly by cryopreservation (Almlid and Johnson, 1988; Eriksson and Rodriguez-Martinez, 1996; Rodriguez-Martinez et al., 1996; Woelders et al., 1996). In the present study, the traditional sperm quality parameters, that is, motility and viability, were significantly decreased after the freezing and thawing procedure and an approximate reduction of $50 \%$ was observed in sperm viability and of $40 \%$ in sperm motility. The magnitude of the loss in sperm quality differed according to the initial quality of the semen: that is, poor quality semen (class L) was more affected, with up to 66 and $51 \%$ relative decreases in viability and motility, respectively. Furthermore, the relative loss of motility between 1 and $6 \mathrm{~h}$ after thawing increased progressively according to the decrease in semen quality from classes $\mathrm{H}$ through $\mathrm{A}$ to $\mathrm{L}$. In contrast, Woelders et al. (1996) concluded that semen quality before and after 
freezing were not related, whereas the breeding line was suggested as a significant source of variation in determining the proportions of motile spermatozoa with normal apical ridge (NAR) in thawed semen.

The fatty acid composition of boar semen was similar to that reported in previous studies (Poulos et al., 1973; Paulenz et al., 1995), with relatively high proportions of $22: 5 n-6$ and 22:6n-3. The total sperm lipid content increased significantly in classes $\mathrm{H}$ and $\mathrm{A}$ after freezing and thawing compared with the content of fresh cells. The lipids gained during storage were mainly triacylglycerols and, to a lesser extent, phospholipids. If this increase in the lipid content of spermatozoa had been passive (that is, due to contamination from the egg yolk-based diluent or inefficient washing procedure), it would have been expected to occur in a similar fashion in all three classes, which did not prove to be the case. Therefore, we suggest that an active cellular lipid metabolism responsible for lipid transfer or synthesis occurs during incubation of spermatozoa within the egg yolkbased diluent or after the freezing and thawing procedure. Previous studies have reported the ability of egg yolk lipoproteins to bind strongly to the sperm plasma membrane in bulls (Cookson et al., 1984; Vishwanath et al., 1992). Moreover, sperm cells can exchange lipid components with the extracellular environment (Neill and Masters, 1972, 1973; Vasquez and Roldan, 1997) and, furthermore, Buhr et al. (1999) suggested a link between successful cryopreservation of boar semen and a given mixture of lipids and fatty acids in the original diluent. Once again, a specific role for the lipids present in the diluent or exchanges with spermatozoa are indicated. The present data also indicate that there was not only an uptake of lipid by sperm cells but also that this uptake was related to the quality of fresh semen. Phospholipase activities may mediate this lipid metabolism, totally or in part (for review, see Roldan, 1998). Buhr et al. (1994) reported an increase in the content of phospholipids, and in particular of phosphatidylcholine, during the cryopreservation of boar spermatozoa in the presence of egg yolk. The exact role of yolk components has not yet been clarified. Phosphatidylcholine (also called lecithin) has been proposed as the protective component during freezing (Quinn et al., 1980) since it prevented ultrastructural damage and favoured the maintenance of motility and respiration (Simpson et al., 1987). In contrast, studies have shown that phosphatidylcholine had no effect on boar sperm damage (Pursel et al., 1973) and did not prevent motility loss during cold shock and storage at $5^{\circ} \mathrm{C}$ (Watson, 1981). Phosphatidylserine has also been proposed as a protective agent in the boar (Butler and Roberts, 1975; Foulkes, 1977). Cationic low density lipoprotein (LDL) of egg yolk, characterized by a specific lipid:protein ratio of 2.7 , was found to be the most efficient in protecting bull spermatozoa against cold shock. The cationic protein moiety of the LDL complex bound strongly to the sperm plasma membrane, which is negatively charged, and the lipid moiety was responsible for the protective action (Vishwanath et al., 1992).
In contrast to changes in triacylglycerols and phospholipids, a general loss in the free cholesterol content occurred in spermatozoa after freezing and thawing and a significant difference was measured in class A boars. The loss in sperm cholesterol content is a feature of capacitation (Therien et al., 1998; Visconti et al., 1999). Furthermore, several reports have suggested that cryopreservation increases the proportion of capacitated spermatozoa (Watson, 1995; Gillan and Maxwell, 1999; Maxwell et al., 1999) and that cooling to $4^{\circ} \mathrm{C}$ induces capacitation-like changes in mouse spermatozoa (Fuller and Whittingham, 1997). The results of the present study support this theory by indicating a loss of cholesterol, which is a characteristic event of capacitation, in cryopreserved spermatozoa.

Alvarez and Storey (1992) demonstrated that cryopreservation enhanced peroxidation in human spermatozoa. A negative correlation between motility and peroxidation was reported during cryopreservation of spermatozoa (Bell et al., 1993). The results of the present study showed that semen samples with the highest viability after freezing and thawing were also characterized by high SOD activity and high proportion of GSH-Px-Se before freezing. However, no significant differences were found among classes in fresh antioxidant enzymatic activities and more data are needed to confirm their importance in successful cryopreservation. There was a general increase in sperm SOD activity after cryopreservation and the difference was particularly marked in spermatozoa with low freezability. Such an increase in SOD activity is unusual as no activity was found in the freezing extender (data not shown). It is possible that the differences in SOD activity were the result of the enzyme extraction procedure having different efficiency on fresh and frozen-thawed cells. In contrast, a $50 \%$ decrease in SOD activity was measured after freezing and thawing in bull spermatozoa (Bilodeau et al., 2000). The results of the present study indicate a need for $\mathrm{O}_{2}{ }^{-}$and $\mathrm{H}_{2} \mathrm{O}_{2}$ scavengers. SOD scavenges $\mathrm{O}_{2}{ }^{-}$and generates $\mathrm{H}_{2} \mathrm{O}_{2}$, which is in turn scavenged by GSH-Px-Se. An increased generation of $\mathrm{H}_{2} \mathrm{O}_{2}$ in class $L$ spermatozoa after thawing may account for the lower quality of this sample (that is, the system might lack $\mathrm{H}_{2} \mathrm{O}_{2}$ scavengers).

In conclusion, traditional sperm quality parameters are related to the ability of the gametes to survive cryopreservation. High sperm viability before freezing is indicative of both high viability and motility after freezing and thawing. Fresh sperm quality also affects the changes occurring in sperm lipid content after the cryopreservation process, which includes the incubation into the egg yolk-based diluent, and the freezing and the thawing techniques. The best quality gametes after cryopreservation are enriched in lipid, triacylglycerol and phospholipid. More studies are needed to investigate further the mechanism of lipid uptake and its relationship to the freezability of boar spermatozoa.

The authors are grateful to the British Department of Trade and Industry and Scotia Pharmaceuticals (UK) for a post doctoral grant 
to A. Maldjian. They also wish to thank Elpzoo Spa (Italy) for providing semen samples and collaboration for this work.

\section{References}

Almlid T and Johnson LA (1988) Effects of glycerol concentration, equilibration time and temperature of glycerol addition on post-thaw viability of boar spermatozoa frozen straws Journal of Animal Science 66 2899-2905

Almlid T, Stavne SE and Johnson LA (1987) Fertility evaluation of the straw freezing technique for boar semen under practical artificial insemination conditions Zuchthygiene 22 193-202

Alvarez JG and Storey BT (1992) Evidence for increased lipid peroxidative damage and loss of superoxide dismutase activity as a mode of sublethal cryodamage to human sperm during cryopreservation Journal of Andrology 13 232-241

Ammerman CB, Chapman HL, Bouwman GW, Fontenot JP, Bagley CP and Moxon AL (1980) Effect of supplemental selenium for beef cows on the performance and tissue selenium concentrations of cows and suckling calves Journal of Animal Science $\mathbf{5 1}$ 1381-1386

Bell M, Wang R, Hellstrom WJG and Sikka SC (1993) Effect of cryoprotective additives and cryopreservation protocol on sperm membrane lipid peroxidation and recovery of motile human sperm Journal of Andrology 14 472-478

Bilodeau JF, Chatterjee S, Sirard MA and Gagnon C (2000) Levels of antioxidant defences are decreased in bovine spermatozoa after a cycle of freezing and thawing Molecular Reproduction and Development 55 282-288

Buhr MM, Curtis EF and Somnapan Kakuda N (1994) Composition and behaviour of head membrane lipids of fresh and cryopreserved boar sperm Cryobiology 31 224-238

Buhr MM, He L and Kasimanickam V (1999) Lipids in extenders affect boar sperm function during cryopreservation Proceedings of the 4th International Conference on Boar Semen Preservation O8

Butler WJ and Roberts TK (1975) Effects of some phosphatidyl compounds on boar spermatozoa following cold shock or slow cooling Journal of Reproduction and Fertility 43 183-187

Bwanga CO (1991) Cryopreservation of boar semen I: a literature review Acta Veterinaria Scandinavioa 32 431-453

Christie WW, Noble RC and Moore JH (1970) Determination of lipid classes by gas chromatographic procedure Analyst 95 940-944

Cookson AD, Thomas AN and Foulkes JA (1984) Immunochemical investigation of the interaction of egg-yolk lipoproteins with bovine spermatozoa Journal of Reproduction and Fertility 70 599-604

Eriksson B and Rodriguez-Martinez H (1996) Assessment of membrane damage in frozen-thawed boar spermatozoa. Proceedings III Conference on Boar Semen Preservation Reproduction in Domestic Animals 31 285-286

Foulkes JA (1977) Separation of lipoproteins from egg yolk and their effects on the motility and integrity of bovine spermatozoa Journal of Reproduction and Fertility 49 277-284

Fuller SJ and Whittingham DG (1997) Capacitation-like changes occur in mouse spermatozoa cooled to low temperatures Molecular Reproduction and Development 46 318-324

Garner DL and Johnson LA (1995) Viability assessment of mammalian sperm using SYBR14 and propidium iodide Biology of Reproduction 53 276-284

Gillan L and Maxwell WMC (1999) The functional integrity and fate of cryopreserved ram spermatozoa Journal of Reproduction and Fertilty Supplement 54 271-283

Hamilton S, Hamilton RJ and Sewell P (1992) Extraction of lipids and derivative formation. In Lipid Analysis - A Practical Approach pp 13-64 Eds RJ Hamilton and S Hamilton. Oxford University Press, Oxford

Maxwell WMC, Long CR, Johnson LA, Dobrinsky JR and GR Welch (1999) The relationship between membrane status and fertility of boar spermatozoa after flow cytometric sorting in the presence or absence of seminal plasma Reproduction Fertility Development 10 433-440

Neill AR and Masters CJ (1972) Metabolism of fatty acids by bovine spermatozoa Biochemical Journal 34 279-287
Neill AR and Masters CJ (1973) Metabolism of fatty acids by ovine spermatozoa Journal of Reproduction and Fertility 34 279-287

Parks JE and Lynch DV (1992) Lipid composition and thermotropic phase behaviour of boar, bull, stallion, and rooster sperm membranes Cryobiology 29 255-266

Paulenz H, Taugbol O, Hofmo PO and Saarem K (1995) A preliminary study on the effect of dietary supplementation with cod liver oil on the polyunsaturated fatty acid composition of boar semen Veterinary Research Communications 19 273-284

Pettitt MJ and Buhr MM (1998) Extender component and surfactants affect boar sperm function and membrane behaviour during cryopreservation Journal of Andrology 19 736-746

Poulos A, Darin-Bennett A and White IG (1973) The phospholipid-bound fatty acids and aldehydes of mammalian spermatozoa Comparative Biochemistry and Physiology 46B 541-549

Pursel VG, Johnson LA and Schulman LL (1973) Effect of dilution, seminal plasma and incubation period on cold shock susceptibility of boar spermatozoa Journal of Animal Science 37 528-531

Quinn PJ, Chow PYW and White IG (1980) Evidence that phospholipid protects ram spermatozoa from cold shock at a plasma site Journal of Reproduction and Fertility $60403-407$

Rodriguez-Martinez H, Eriksson B and Lundeheim N (1996) Freezing boar semen in flat plastic bags: membrane integrity and fertility. Proceedings III Conference on Boar Semen Preservation Reproduction in Domestic Animals 31 161-168

Roldan ERS (1998) Role of phospholipases during sperm acrosomal exocytosis Frontiers in Bioscience 3 D1109-D1119

SAS (1998) SAS/STAT User's Guide Vol. 2, Version 6, 4th Edn. SAS Institute Inc., Cary, NC

SCAN (1995) Software for Chemometric Analysis Release 1. Minitab Inc., State College, PA

Simpson AM, Swan MA and White IG (1987) Susceptibility of epididymal boar semen to cold shock and protective action of phosphatidylcholine Gamete Research 17 355-373

Therien I, Moreau R and Manjunath P (1998) Major proteins of bovine seminal plasma and high-density lipoprotein induce cholesterol efflux from epididymal sperm Biology of Reproduction 59 768-776

Vasquez JM and Roldan ERS (1997) Phospholipid metabolism in boar spermatozoa and role of diacylglycerol species in the de novo formation of phosphatidylcholine Molecular Reproduction and Development $\mathbf{4 7}$ 105-112

Visconti PE, Xiaoping N, Fornes MW, Alvarez JG, Stein P, Connors SA and Kopf GS (1999) Cholesterol efflux-mediated signal transduction in mammalian sperm: cholesterol release signals an increase in protein tyrosine phosphorylation during mouse sperm capacitation Developmental Biology 214 429-443

Vishwanath R, Shannon P and Curson B (1992) Cationic extracts of egg yolk and their effects on motility, survival and fertilising ability of bull sperm Animal Reproduction Science 29 185-194

Watson PF (1981) The roles of lipid and protein in the protection of ram spermatozoa at $5^{\circ} \mathrm{C}$ by egg-yolk lipoprotein Journal of Reproduction and Fertility 62 483-492

Watson PF (1995) Recent developments and concepts in the cryopreservation of spermatozoa and the assessment of their post-thawing function Reproduction Fertility Development 7 871-891

Westendorf P, Richter L and Treu H (1975) Zur tiefgefrierung von ebersperma Labor - und Besamungsergebnisse mit dem Hulsenberger Pailletten Verfahren Deutsche Tierarztliche Wochenschrift 82 261-267

Woelders H, Matthijs A and Den Besten M (1996) Boar variation in 'freezability' of the semen. Proceedings III Conference on Boar Semen Preservation Reproduction in Domestic Animals 31 153-159

Woolliams JA, Wiener G, Anderson PH and McMurray CH (1983) Variation in the activities of glutathione peroxidase and superoxide dismutase and in the concentration of copper in the blood in various breed crosses of sheep Research in Veterinary Science 34 253-256

Revised manuscript received 16 June 2000.

Accepted 2 October 2000. 
